\title{
Секреты устойчивости бизнеса в условиях пандемии
}

\author{
Рассказывает Евгений Владимирович Шохин, генеральный директор \\ ООО "Сарториус Рус»
}

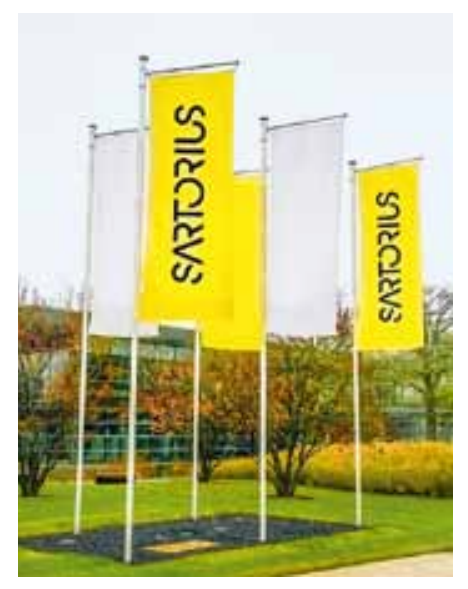

\begin{abstract}
Пандемия коронавируса стала серьезным вызовом для бизнеса во всем мире, в том числе и для ведущих международных производителей. О том, как в условиях неопределенности развивается бизнес концерна Sartorius AG - поставщика комплексных решений и высокоточного оборудования, мы беседуем с генеральным директором ООО "Сарториус рус" Евгением Владимировичем Шохиным, ответственным за направление "Лабораторные продукты и услуги»в России и СНг.
\end{abstract}

\section{Концерн Sartorius AG отмечает в этом году свое 150-летие. Какие основные вехи в его истории вы отметили бы?}

Отправная точка истории компании Sartorius - создание первых в мире весов с укороченным коромыслом. Для того времени, второй половины 19 века, это было революционное решение. Следующей вехой стал прорыв в первой половине 20 века в таком новом для отрасли направлении, как мембранная фильтрация. Его компания Sartorius развивала совместно с Рихардом Зигмонди, получившим Нобелевскую премию по химии за установление гетерогенной природы коллоидных растворов и разработку фундаментальных методов коллоидной химии. Также мы гордимся тем, что в 70-х годах 20 века наше оборудование использовалось в исследовании первого образца лунного грунта. Позднее компания Sartorius продолжила свое новаторство, первой представив в аналитических весах монолитную весовую ячейку, а на рубеже 20 и 21 веков взяла верный стратегический курс на развитие биофармацевтики и одноразовых технологий.

Изучая историю компании, мы узнали, что первое зарубежное представительство Sartorius было открыто в 1910 году в Санкт-Петербурге. Самостоятельно вернулась в Россию она уже после перестройки, в 1991 году, организовав в городе на Неве совместное предприятие с заводом "Госметр".
Как сегодня устроен бизнес компании Sartorius AG в мире и в России? Какова структура ее доходов?

Глобально концерн Sartorius развивает два направления: комплексные решения (системы и оборудование для биофармацевтической отрасли) и инновационные лабораторные продукты и услуги. К последним относятся решения для лабораторной фильтрации, водоподготовки, продукты для лабораторного дозирования и микробиологического контроля и, конечно, весоизмерительное оборудование. Это направление Lab Products\&Services развивает в России компания ООО "Сарториус РУС", которой я руковожу. Мы работаем с фармацевтическим рынком и со многими другими отраслями, такими как добыча полезных ископаемых, медицина, энергетика и многие другие.

Глобально биофармацевтическое направление занимает в обороте концерна две трети, остальное - лабораторное оборудование. В России ситуация немного другая. Здесь исторически все начиналось с лабораторного направления, именно для его развития и было создано СП "Сартогосм". С 2019 года оба направления делают примерно одинаковый вклад в бизнес Sartorius в России и СНГ. Мы также видим, что сегодня у направления биопроцессов концерна Sartorius в России большие перспективы и потенциал: текущая ситуация в регионе, 
востребованность новых вакцин спровоцировали колоссальный спрос на продукцию для биопроцессов. А наши коллеги как раз продвигают решения, которые используются для производства вакцины.

\section{Как бы вы оценили вклад компании "Сарториус РУС" в оборот глобального направ- ления лабораторных продуктов и сервисов концерна Sartorius?}

Наш вклад в совокупный объем продаж всех лабораторных продуктов и услуг концерна пока не очень большой, по моим оценкам, около 3-4\%. Но мы двигаемся вместе с концерном Sartorius AG к общей стратегической цели - увеличению оборота до 4 млрд евро к 2025 году (нынешний, 2020 год, по прогнозам будет завершен на уровне 2,2 млрд евро), соответственно, мы, как и наши коллеги, ставим себе задачу ежегодного двухзначного процентного роста.

\section{Каковы драйверы роста направления лабора- торных продуктов и сервисов в России?}

В целом для всего концерна глобальные драйверы это демографический рост, запрос человечества на прорывные решения в борьбе с онкологическими заболеваниями, расширение производства биоэквивалентных препаратов, потребность в увеличении вакцинации населения.

Для лабораторного направления в России и СНГ основным драйвером и темой № 1 этого года является диагностика вирусов, поскольку в портфеле Sartorius есть продукция, которая помогает диагностическим лабораториям выявлять коронавирус. Мы также предлагаем оборудование и материалы, которые используются в тестовых системax.

Росту бизнеса в России способствуют государственные программы, направленные на поддержку фармацевтики и здравоохранения. Например, имплементация международных отраслевых стандартов GMP (Good Manufacture Practice) и GLP (Good Laboratory Practice). Поскольку Sartorius предлагает решения для компаний, которые интегрировали в свой бизнес эти стандарты и соблюдают их, концерн с оптимизмом смотрит на российский рынок.

Важно также упомянуть, что мы готовы увеличивать долю клиентов, делающих выбор в пользу работы с производителем оборудования напрямую.

\section{А какие факторы вы считаете сдерживаю- щими бизнес лабораторного направления в России?}

С моей точки зрения, это бюрократия и излишняя зарегулированность российского медицинского рынка, отсутствие возможности у некоторых клиентов работать напрямую с иностранными производителями. Также в силу географического положения и политической конъюнктуры на наш бизнес оказывает давление мощная экспансия китайских производителей. Поскольку наше оборудование производится в Германии и Финляндии, соревноваться по цене с компаниями из Поднебесной достаточно сложно.

В то же время в конкурентной борьбе мы уверенно выигрываем у них по качеству решений и оборудования, особенно сейчас, в ситуации пандемии, когда есть большой спрос на скорость и безошибочность диагностики и высокое качество тестирования. Недаром наши продукты сегодня используются практически всеми ведущими российскими диагностическими клиническими лабораториями.

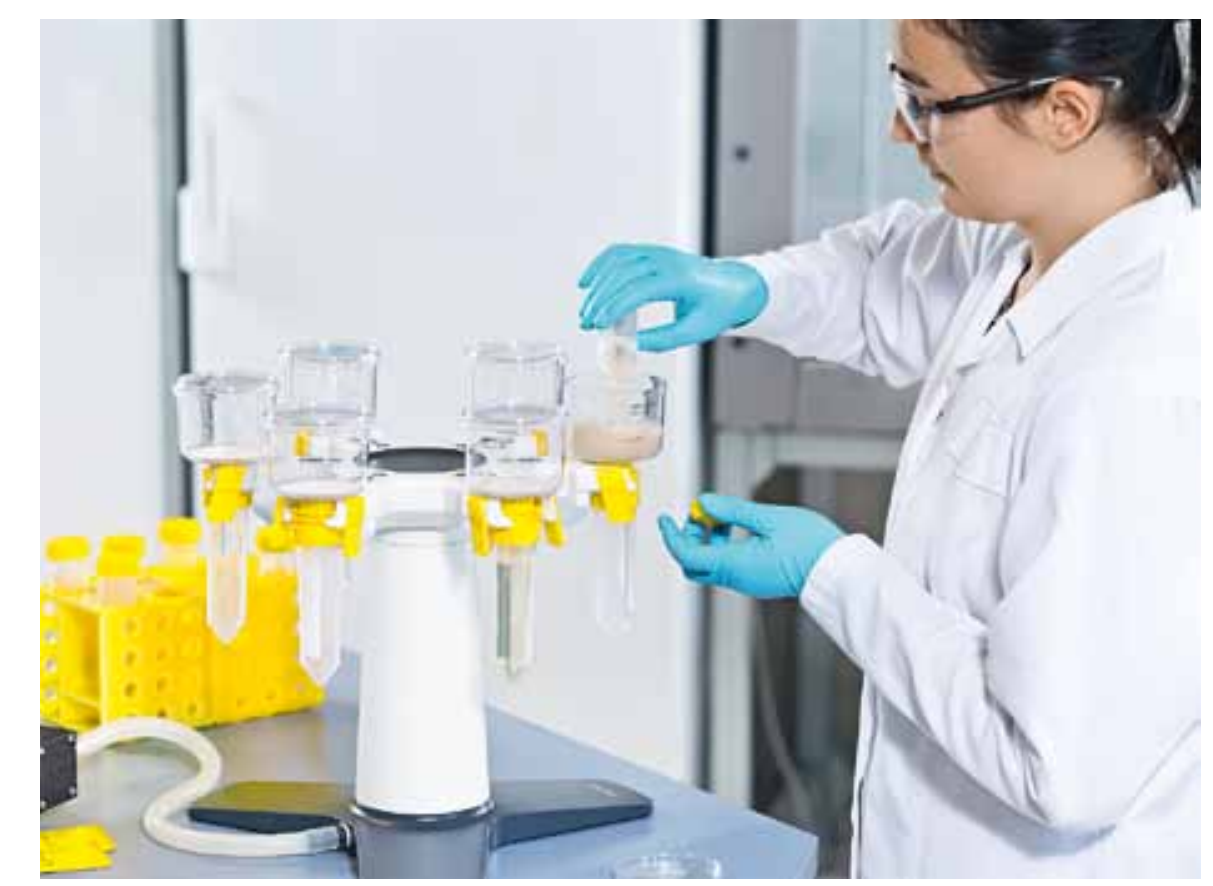




\section{Вы наверняка анализировали проблемы, с которыми столкнулись в начале пандемии ваши заказчики, пользователи лабораторного оборудования Sartorius. Поделитесь, пожа- луйста, выводами.}

Начнем с того, что мы увидели огромный скачок спроса на продукцию для разработки и исследования вакцин и на диагностику. При этом, как оказалось, так называемые "доковидные" процессы согласования не поддерживают необходимый в новых условиях высокий темп принятия решений. Сегодня немало клиентов, которые пересматривают процессы согласования тендеров и закупок. Безусловно, также повлияла на работу с клиентами и необходимость перевода сотрудников на удаленную работу.

И, как я уже говорил, возросла важность качественных расходных материалов при проведении диагностики для сокращения доли ложных результатов тестирования. Так что качественное оборудование и расходные материалы стали значить еще больше в связи с наращиванием объемов тестирования.

А как развивался ваш бизнес на других рынках, где продается лабораторное оборудование Sartorius?

На немедицинских рынках в России, не связанных с коронавирусом, ситуация в этом году, конечно же, намного усложнилась. У нас много клиентов из добывающих отраслей, и мы видим, что в большинстве своем они были вынуждены очень сильно сократить или даже заморозить бюджеты, запланированные на покупку качественного лабораторного оборудования, в том числе и нашего. Ситуация в экономике, падение потребительского спроса заставили их заняться оптимизацией закупочной деятельности.

Нефтяники столкнулись с огромной волатильностью цен на своем рынке. Компании, которые практикуют вахтовый метод работы сотрудников, пережили ситуации, связанные с распространением коронавируса: если заболеет один вахтовик, то существуют серьезные риски, что заразятся все, и работа на предприятии полностью остановится. Некоторые наши клиенты из компаний, которые занимаются добычей золота и алмазов, почувствовали всю остроту этой проблемы на себе.

\section{Трудности, выпавшие в этом году на долю клиентов, как-то скажутся на финансовых результатах компании "Сарториус РУС" по итогам 2020 года?}

На самом деле судить об этом пока сложно. В начале пандемии нам казалось, что дела идут плохо, потом, в середине лета, компании поняли, что перспективы окончания пандемии, мягко скажем, туманны, и начали изыскивать средства и все-таки проводить тендеры и закупки высокоточного лабораторного оборудования. Так что ситуация по результатам третьего квартала вроде бы начала выравниваться.

Изначально в этом сегменте мы ставили цель - добиться значительного роста, но сейчас понимаем, что клиентам приходится нелегко. Так что на немедицинских рынках, не связанных с диагностикой коронавируса, по итогам этого года мы стремимся выйти на результаты 2019-го. И тут у нас неплохие шансы. Некоторые немедицинские лаборатории, несмотря ни на что, пытаются изыскать ресурсы на закупку высокоточного оборудования Sartorius, потому что не хотят и не могут останавливать процессы контроля качества и количества.

И понимая всю сложность текущей ситуации для потенциальных покупателей наших решений, мы стараемся находить взаимовыгодные условия, на которых такие клиенты могли бы произвести закупку, работаем с каждой компанией индивидуально.

За период между двумя волнами пандемии появились ли в продуктовом портфеле концерна Sartorius какие-то новые решения?

Специфика рынка высокоточного лабораторного оборудования заключается в том, что новинки на нем быстро не появляются. К тому же пока из-за кардинально меняющихся условий не очень понятно, какие решения будут востребованы в среднесрочной перспективе. Концерн Sartorius производит сложное оборудование, поэтому не видим смысла в том, чтобы инвестировать в разработку продуктов, которые будут пользоваться спросом только в какой-то ограниченный период времени.

Но вместе с тем мы смогли найти применение в новой реальности нашего оборудования для решения других, более узких задач. Я имею в виду 
решения Sartorius в области микробиологического контроля воздуха, оборудования дозирования, которые были актуализированы для удовлетворения потребностей общества в средствах борьбы с пандемией.

В частности, у нашей компании есть оборудование для мониторинга воздуха, выявления вирусов, которое применяется для отбора проб воздуха на желатиновые мембранные фильтры или чашки с агаровой средой. Речь идет о портативном пробоотборнике воздуха MD-8. В России этот прибор пока не пользуется большим спросом из-за законодательной неурегулированности, но за рубежом - в Китае, Европе запросы в компанию Sartorius на его приобретение выросли колоссально. Мы считаем, что в будущем и в России это оборудование будет востребовано.

Также, безусловно, компания перестраивается под растущий спрос на расходные материалы для дозирующего оборудования.

Наконечники для дозаторов, которые используются для диагностики коронавируса, сейчас на пике спроса. Сегодня приходится пересматривать линейку, переносить акцент на производство самых востребованных артикулов.

Но надо понимать, что процесс этот небыстрый, потому что продукция поставляется на медицинский рынок, где требуется отдельная сертификация, валидация производственных линий. Этим мы занимаемся уже с весны, когда столкнулись с глобальным спросом. Я сейчас говорю о направлении лабораторных решений. Коллеги из биопроцессов смогут рассказать больше и о своем направлении, потому что их оборудование непосредственно используется для разработки и производства вакцин.

\section{Какие уроки компания "Сарториус РУС" вынесла из первой волны пандемии?}

Мы и раньше считали, что основной актив - наши люди, наши сотрудники. И события первой волны коронавируса действительно показали нам, что здоровье сотрудников - это важнейший фактор. В весенние месяцы мы перевели часть работников на удаленную работу. А для защиты тех, кто не мог исполнять свои должностные обязанности из дома, - работников нашей логистической службы, складского хозяйства и производства - приняли меры, потребовавшие дополнительных затрат, о которых мы и сейчас не жалеем.

Мы обеспечили всех сотрудников, продолжающих работать в офисе и на складе, средствами защиты в необходимом объеме. Строго выполняли, хоть это и потребовало дополнительных усилий, все постановления, стандарты Роспотребнадзора. Где это было необходимо, старались минимизировать передвижение сотрудников на общественном транспорте. В отличие от европейских коллег, особенно из нашего немецкого офиса, где личный или корпоративный автомобиль у каждого сотрудника является нормой, в России дела обстоят иначе, поэтому мы старались помочь сотрудникам комфортно добираться до места работы и обратно.

В самом начале первой волны в компании "Сарториус РУС» был создан оперативный штаб руководителей компании в России, который практически ежедневно анализировал текущую ситуацию.

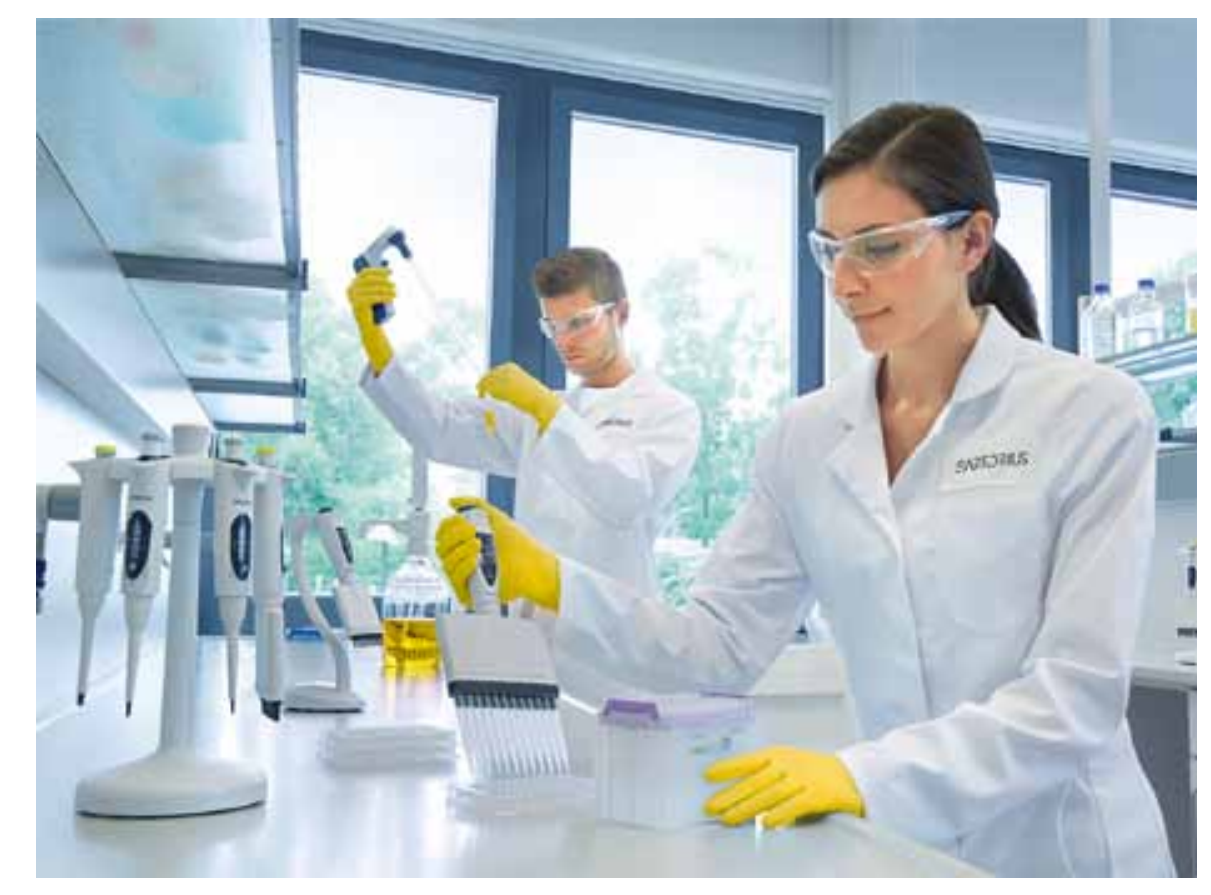




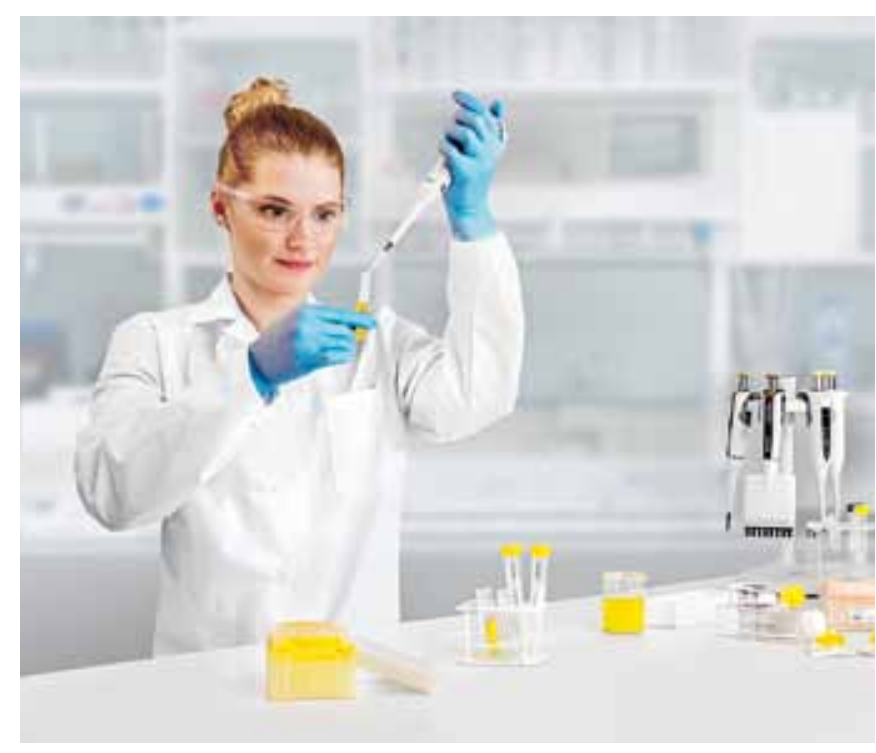

На основе этого анализа предпринимались корректирующие действия.

До пандемии мы не так регулярно собирались для решения оперативных вопросов. Однако быстрое принятие решений показало свою эффективность в новых условиях.

И третий урок - это реагирование на запросы клиентов. Очень важно для нас в эти тяжелые дни, как весной, так и сейчас, не уходить от контакта с клиентами, стараться поддерживать с ними обратную связь, помогать в решении проблем. Люди помнят, как на их запросы реагировали в кризисные дни, и учитывают это при дальнейшей работе с поставщиками оборудования.

\section{А как вы переживаете вторую волну?}

Безусловно, к осени мы подошли еще более подготовленными, уже лучше понимаем, с чем можем столкнуться. Надо сказать, что со взрывным ростом спроса на наконечники дозирующего оборудования, который начался весной и продолжается до сих пор, столкнулись все ведущие производители.

И мы, и наши коллеги по рынку понимаем, что производственные мощности ограничены, и стараемся их увеличить. Поскольку продукция предназначена для медицинского рынка, быстро увеличить объемы выпуска сложно. Нужно следовать всем действующим нормативам и требованиям по безопасности, стерильности и т.д.
А тем временем спрос на наконечники для дозаторов до сих пор растет, рынок далек от насыщения.

\section{Как празднование 150-летия со дня основания глобальной компании Sartorius затронуло Россию?}

К этой знаменательной дате в 2020 году было запланировано очень много мероприятий и в Германии, и в России. Однако, к сожалению, пандемия коронавируса внесла в наши планы серьезные коррективы: отметить юбилей с клиентами и партнерами не удалось. И в ситуации, когда не было возможности собрать на праздник клиентов, мы приняли решение поддержать наших сотрудников. Как только позволила эпидемиологическая ситуация, провели первый в истории "Сарториус" в России корпоративный выезд с семьями и близкими. И надо сказать, что наши сотрудники восприняли это очень позитивно.

Как показали события этого года, основной актив компании "Сарториус РУС" - это сотрудники. А празднование 150-летия концерна Sartorius с российскими клиентами мы немного отсрочили, но надеемся, что очень скоро это осуществим!

\section{В чем же, на ваш взгляд, заключается секрет устойчивости компании "Сарториус РУС» в нынешних непростых условиях?}

Начну, наверное, с основополагающих вещей, поскольку они имеют большое значение сейчас, - это бренд Sartorius, качество продукции, надежность поставок. Очень важным фактором в условиях пандемии стала клиентская поддержка практически в круглосуточном режиме, с учетом того, что у нас много клиентов в Сибири и на Дальнем Востоке. Еще один фактор - уникальные решения, о которых я сказал выше. И, конечно, наша готовность принимать решения в условиях неопределенности. Решение оставить работников склада и логистики на рабочих местах в апреле-мае для полноценного исполнения обязательств перед клиентами было непростым, но мы его приняли. Все это, а также наша дружная команда, и формирует устойчивость и успех компании!

\section{I Спасибо за интересный рассказ.}

С Е.В.Шохиным беседовала А.Е.Крылова. 


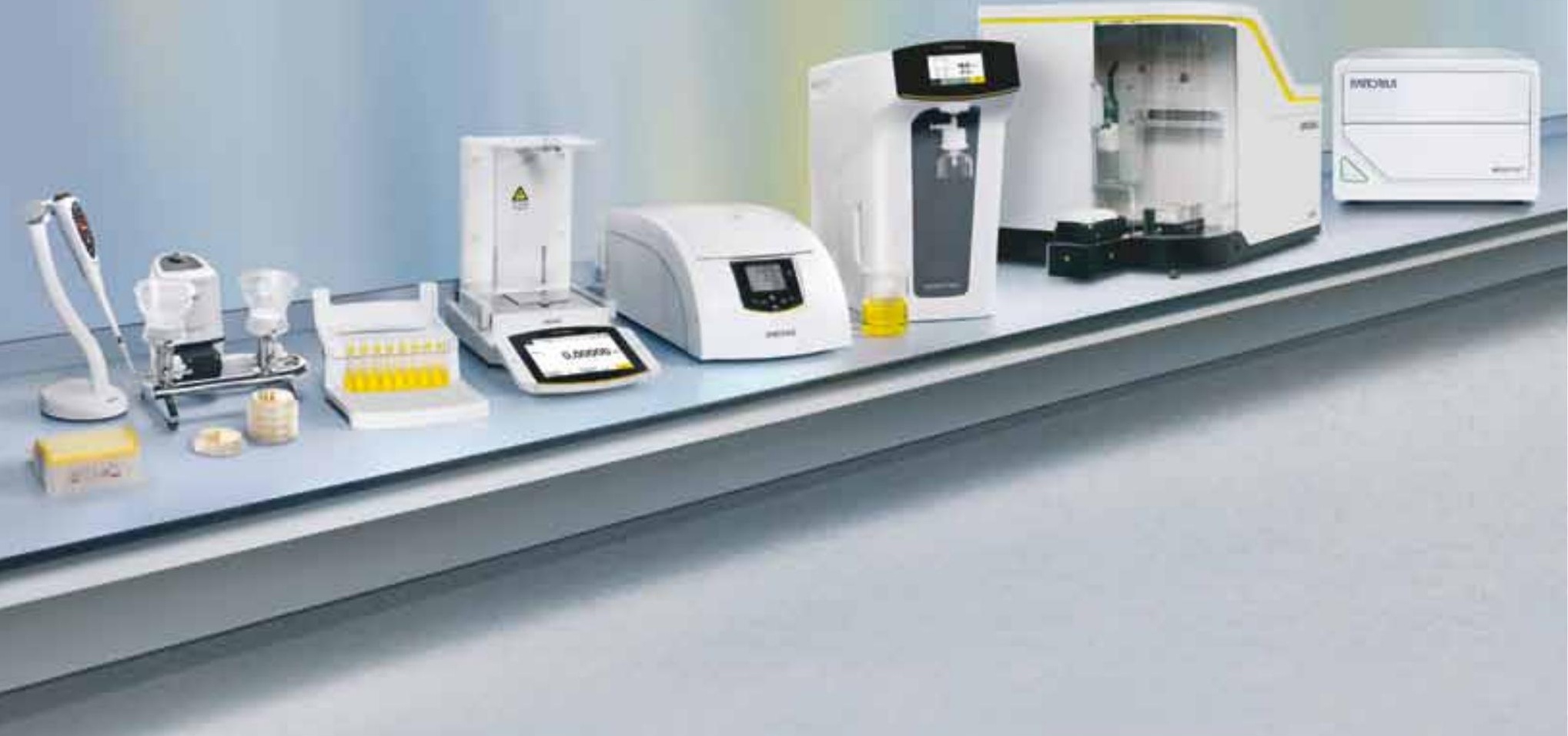

Решения Sartorius

\section{Simplifying Progress} для лабораторий

Дозаторы и наконечники, лабораторные весы, системы водоподготовки, микробиологический контроль, биоаналитика, сервис 